\title{
A New Spice Macromodel of 4H-SiC Vertical Double Implanted MOSFET (DIMOS)
}

\author{
Messaadi Lotfi", Dibi Zohir, Smail Toufik \\ Department of Electronics, University of Batna, Advanced Electronic Laboratory (LEA),Av. El HadiBoukhloufBatna, 05000, Algeria
}

\begin{abstract}
The4H-SiCvertical double Implanted MOSFET (DIMOS) offers advantages over conventional silicon devices, enabling high system efficiency and/or reduced system size, weight and cost through its higher frequency operation. Compared to the best silicon IGBTs, the $\mathrm{SiC}$ device will improve system efficiency up to $2 \%$ and operate at $2-5$ times the switching frequencies.In this paper we present an equivalent circuit Spice of 4H-SiC DIMOSFET for a wide temperature range. Simulation for DC characteristics (I-V) of the SiC MOSFET with the exact device geometry is carried out using the commercial device simu lator Spice. All Spice parameters are extracted from the measurements, and a SPICE model for the DIMOS transistor has been developed and implemented in the circuit simulator Orcad PSpice 10.5. The temperature dependent behaviour was simulated and analysed. A good agreement between the Spice simulation and analytical model evaluation for SiC DIMOS is demonstrated. Model parameters can be adjusted to obtain an optimum device to be used in power system applications.
\end{abstract}

Keywords Power Device, 4H-SiC DIMOSFET, Macromodel, Analytical Model, Spice, Temperature Variation Effect

\section{Introduction}

With increasing global emphasis on energy efficiency, improved power devices are critical to the development of the next generation of power systems. Increasing the efficiency of power conversion systems produces multiple benefits. Increasing the efficiency of a system has the obvious benefit of increasing the power output of the system[1], and it also has the benefit of reducing the amount of waste heat being generated, leading directly to a reduction in the size, weight and complexity of the cooling system. Further decreases in size and weight can be achieved by operating the system at a higher frequency, thereby reducing the number and mass of passive components.

$\mathrm{SiC}$, a wide bandgap semiconductor material has an electric-field breakdown capability that is ten times that of silicon and also has excellent thermal conductivity. $\mathrm{SiC}$ is also a robust material since it is both physically hard and maintains its properties at extremely high temperatures [2].

Although there are no commercially available power MOSFETs in $\mathrm{SiC}$ material, Cree has demonstrated various switching devices in $\mathrm{SiC}$ A group from Purdue University proposed a DIMOS in $6 \mathrm{H}-\mathrm{SiC}$ with a breakdown voltage of 760 V[3] Presently, most of the research effort in $\mathrm{SiC}$ is on

* Corresponding author:

lotfi.messaadi@gmail.com (Messaadi Lot fi)

Published online at http://journal.sapub.org/msse

Copyright (C) 2012 Scientific \& Academic Publishing. All Rights Reserved the design and fabrication of power MOSFETs. However, theoretical models of these prototypes have to be developed to study the behaviour of these devices and fine-tune their characteristics. Since SiC MOSFETs are still in their infancy, there is a good opportunity now to study and model these devices so that the model can be verified using actual $\mathrm{SiC}$ MOSFET test devices. A good reliable device model is essential for the evaluation of the device behaviour and its characteristics[3]. A precise model can predict the device behaviour more accurately and thus, the design requirements can be implemented with tight tolerances. This paper provides a brief overview of the state-of-the-art research in the area of silicon carbide device modelling. A thorough and detailed analysis of a SiC power MOSFET, modelling, simulation, testing, and characterization of a test device and the extraction of parameters for a SPICE model are presented. $\mathrm{SiC}$ offers significant advantages for power electronics applications such as lamp ballasts, motor controls, medical electronics, automotive electronics, highdensity high-frequency power supplies and smart-power application-specific integrated circuits. Hence, silicon carbide-based MOSFET can be used in high power application and hence MOSFETs require a high breakdown voltage. The one-step field plate termination can enhance the breakdown voltage to $910 \mathrm{~V}$, embedded mesa termination can increase it to $1350 \mathrm{~V}$ and the embedded mesa with step field plating can give a breakdown voltage of $1100 \mathrm{~V}$. However, 4H-SiC DIMOSFETs in practice have attained a maximum blocking voltage of $760 \mathrm{~V}$. The specific on-resistance of the drift region of the MOSFET 
can be significantly reduced by enhancing the inversion channel mobility using phytogenic re-oxidation annealing thereby reducing the power dissipation. The present work aims at estimating theoretically the breakdown voltages, power dissipation and specific on-resistance at various doping levels by varying the drain voltage[4].The long term goal of this program is to develop $\mathrm{SiC}$ power switches with a $2.5 \mathrm{kV}$ blocking voltage and a $50 \mathrm{~A}$ current rating for insertion into motor control modules operating at temperatures as high as $200^{\circ} \mathrm{C}$.

\section{Modelling of Vertical DIMOS Device}

\subsection{Model}

An analytical model for a DIMOS field effect transistor is developed using $\mathrm{SiC}$ material[5]. The model is developed based on the methodology for a vertical double diffusion MOS model. The proposed DIMOS model incorporates the effect of SiC device behaviour. Figure 1 shows the details of the device structure identifying the different regions of operation. The model is developed from regional analyses of carrier transport in the channel and the drift regions. The active channel exists below the oxide layer and within the p-bodies.

The current/voltage characteristic in the triode region is given by Eq. 1

$$
\begin{gathered}
I_{C H}=\frac{W \cdot \mu_{n}}{2 L\left[1+\left(\frac{\mu_{n}}{v_{s a t} L}\right) V_{c h}\right]} V_{c h}\left[2 C_{O X}\left(V_{G S}-V_{T}\right)\right. \\
\left.-\left(C_{O X}+C_{d 0}\right) V_{C H}\right]
\end{gathered}
$$

Where:

W : channel width, L : channel length, Vch: channel voltage, $\mathrm{V}_{\mathrm{T}}$ : threshold voltage, $\mathrm{V}_{\mathrm{GS}}$ : gate voltage, $\mathrm{C}_{\mathrm{ox}}$ : oxide capacitance, $\mathrm{C}_{\mathrm{do}}$ : body depletion capacitance, $\mu_{\mathrm{n}}$ : electron mobility, and vsat is the electron saturation velocity.

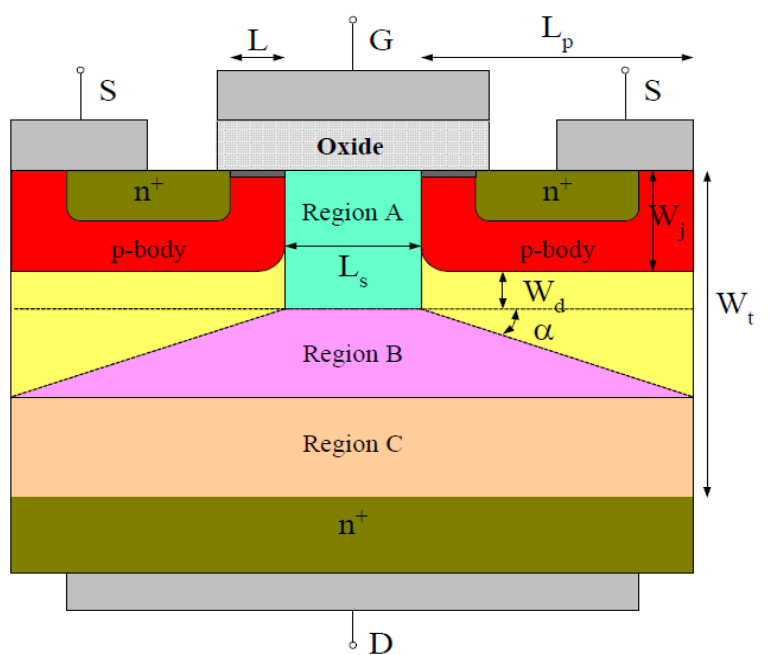

Figure 1. DIMOS structure for modeling. Labels describe the different regions and dimensions of the vertical structure

The drift region is divided into three parts: an accumulation region-A, a drift region-B with a varying cross-section area, and a drift region-C with constant cross-section. The corresponding voltages to these regions are $\mathrm{VA}, \mathrm{VB}$, and $\mathrm{VC}$ for region $\mathrm{A}, \mathrm{B}$, and $\mathrm{C}$, respectively, and they are given by the following equation

$$
\begin{gathered}
V_{A}=\int_{0}^{W_{j}+W_{d}} E_{y} d y=\frac{I_{D}\left(W_{j}+W_{D}\right)}{\left.W\left[L_{S} \cdot q \cdot N_{D} \cdot \mu_{n}\right)-I_{D} / E_{C}\right]} \\
V_{B}=\frac{I_{D}}{W \cdot q \cdot N_{D} \cdot \mu_{n} \cot \alpha} \log \left[\frac{W \cdot q \cdot N_{d} \cdot \mu_{n}\left(L_{S}+2 L_{p}\right)-\frac{I_{D}}{E_{C}}}{W \cdot q \cdot N_{D} \cdot L_{S} \cdot \mu_{n}-\frac{I_{D}}{E_{C}}}\right] \\
V_{C}=\frac{I_{D}\left(W_{t}-W_{j}-W_{d}-L_{P} \tan \alpha\right)}{W \cdot q \cdot N_{D} \cdot \mu_{n}\left(L_{S}+2 L_{P}\right)-I_{D} / E_{C}}
\end{gathered}
$$

Where:

$\mathrm{Wj}$ : depth of $\mathrm{n}+$ contact region, $\mathrm{Wd}:$ depth of depletion region, Wt : total thickness of epilayer, Ls : length of accumulation region, and $\mathrm{Lp}$ is the length of p-body.

Total drift region voltage is

$$
\mathrm{V}_{\text {DRIFT }}=\mathrm{V}_{\mathrm{A}}+\mathrm{V}_{\mathrm{B}}+\mathrm{V}_{\mathrm{C}}
$$

the voltage across the drain and the source is :

$$
\mathrm{V}_{\mathrm{DS}}=\mathrm{V}_{\text {Drift }}+\mathrm{Vch}
$$

The voltages and the currents of the above mentioned two sets of equations for the drift region and the channel region are implicitly related. The drain current, $\mathrm{I}_{\mathrm{D}}$ is equal to the total channel current Ich, which sets a relationship between the two sets of equations. An iterative solver wasdeveloped to evaluate the voltages and the currents. $4 \mathrm{H}-\mathrm{SiC}$ material parameters were used to evaluate the model.

Consider the depletion region between the p-base region and the $n$-drift region as a onedimensional abrupt $p$ - $n$ junction. It can be shown that the doping level $\mathrm{N}_{\mathrm{B}}\left(/ \mathrm{cm}^{3}\right)$ [6] that can support a given breakdown voltage $V_{B}(V)$ and the depletion width $\mathrm{W}(\mathrm{cm})$ at breakdown can be given as:

$$
N_{B}=\frac{\varepsilon E_{C}^{2}}{2 \cdot q \cdot V_{B}}
$$

and

$$
W=\frac{2 . V_{B}}{E_{C}}
$$

where $\mathrm{q}$ is the electron charge.

The specific on-resistance, Ron-sp $\left(\Omega-\mathrm{cm}^{2}\right)[6]$ of the drift layer to support $\mathrm{V}_{\mathrm{B}}$ is:

$$
R_{o n-s p}=\frac{w}{q \cdot N_{B} \cdot \mu_{n}^{2}}
$$

Substituting the values of eqs.(7) and (8) in eq.(9):

$$
R_{o n-s p}=\frac{4 v_{B}^{2}}{\varepsilon \cdot E_{c}^{3} \mu_{n}}
$$

The forward blocking voltage in DIMOSFET is given by :

$$
V_{B R}=\frac{1}{2} E_{c} \cdot w=\frac{q \cdot N_{B} \cdot W^{2}}{2 \cdot \varepsilon}
$$

where $\mathcal{E}$ is the permittivity $(\mathrm{F} / \mathrm{cm}), \mathrm{E}_{\mathrm{C}}$ is the critical field of breakdown $(\mathrm{V} / \mathrm{cm})$ and $\mu \mathrm{n}$ is the electron mobility $\left(\mathrm{cm}^{2} / \mathrm{V}-\mathrm{Sec}\right)$.

\section{Device Structure}

A vertical double implanted MOSFET (DIMOS) in $4 \mathrm{H}-\mathrm{SiC}$ is considered for verification of the analytical model developed earlier. The cross-sectional view of the proposed DIMOS structure is shown in Figure 2.

The proposed device structure and the device dimensions are selected in such a way that a practical device can be built 
on the bas is of currently availab le $\mathrm{SiC}$ technology. Since the diffusion process in $\mathrm{SiC}$ is negligible, ion implantation is the only way to form the $\mathrm{p}$-bodies and the $\mathrm{n}+$ region for the vertical structure. Double diffusion is not suitable for $\mathrm{SiC}$ device fabrication. Double implantation technology consists of the deep range acceptor followed by the shallow range donor implantation to build the necessary MOSFET structure.

The thickness and the doping level of the drift region largely determine the breakdown voltage of the device. The larger the thickness of the drift region is, the bigger the blocking voltage is. However, the current $\mathrm{SiC}$ technology has a limitation of the achievable epilayer thickness. In this design, a $3 \mathrm{kV}$ MOSFET is considered, and the corresponding epilayer thickness is taken as $25 \mu \mathrm{m}$. Based upon the recent $\mathrm{SiC}$ fabrication technology, this epilayer thickness is certainly achievable. Recently, Agarwal and alain[7] achieved epilayer thic kness of about $115 \mu \mathrm{m}$, which allows the blocking voltage to be around $10 \mathrm{kV}$. The $\mathrm{n}-\mathrm{drift}$ region is usually doped lightly $\left(4 \times 10^{15} \mathrm{~cm}^{-3}\right.$ for this device) to obtain the desired blocking voltage of the MOSFET operation. The $\mathrm{n}+$ regions are doped with $\left(1.5 \times 10^{20} \mathrm{~cm}^{-3}\right)$ Nitrogen, and the p-bodies are formed with $\left(4 \times 10^{17} \mathrm{~cm}^{-3}\right)$ Aluminum implantations. The channel length and the width are taken as $1 \mu \mathrm{m}$ and $400 \mu \mathrm{m}$, respectively. The oxide thickness is $500 \AA$, and the p-bodies are separated by $20 \mu \mathrm{m}$.

Table 1 shows values of doping concentration,electron mobility, drift layer thikness and specific on-resistance as a function of breaksown voltage for ideal $4 \mathrm{H}-\mathrm{SiC}$ and $\mathrm{Si}$ power MOSFETs at room temperature condition[8-10].

Table 1. Values of doping concentration, electron mobility, drift layer thikness and specific on-resistance

\begin{tabular}{ccccc}
\hline $\begin{array}{c}\text { Break down vol tage } \\
\text { Vth }(\mathbf{V})\end{array}$ & $\begin{array}{c}\text { Doping concentration, } \mathbf{N}_{\mathbf{B}} \\
\left(\mathbf{c m}^{-3}\right)\end{array}$ & $\begin{array}{c}\text { Electron mobility, } \\
\boldsymbol{\mu}_{\mathbf{n}}\left(\mathbf{c m}^{2} / \mathbf{V s}\right)\end{array}$ & $\begin{array}{c}\text { Thikness } \\
\mathbf{W}_{\mathbf{D}}(\boldsymbol{\mu} \mathbf{m})\end{array}$ & $\begin{array}{c}\text { Specific on-resistance } \\
\mathbf{R o n}\left(\mathbf{\Omega}_{\mathbf{c}} \mathbf{c m}^{2}\right)\end{array}$ \\
\hline & & $4 \mathrm{H}-\mathrm{SiC}$ & \\
$\mathbf{2 0 0}$ & $3.74 .10^{17}$ & 388.95 & & $3.23 .10^{-6}$ \\
$\mathbf{5 0 0}$ & $1.04 .10^{17}$ & 606.54 & 0.75 & $3.24 .10^{-5}$ \\
$\mathbf{1 0 0 0}$ & $3.93 .10^{16}$ & 745.55 & 2.26 & $1.11 .10^{-4}$ \\
$\mathbf{5 0 0 0}$ & $4.13 .10^{15}$ & 905.05 & 5.19 & $5.98 .10^{-3}$ \\
$\mathbf{1 0 0 0 0}$ & $1.57 .10^{15}$ & 928.11 & 35.83 & $3.50 .10^{-2}$ \\
& & $\mathrm{Si}$ & 82.32 & $3.35 .10^{-3}$ \\
$\mathbf{2 0 0}$ & $1.72 .10^{15}$ & 1351.92 & & $3.30 .10^{-2}$ \\
$\mathbf{5 0 0}$ & $5.06 .10^{14}$ & 1356.50 & 12.48 & $1.88 .10^{-1}$ \\
$\mathbf{1 0 0 0}$ & $2.01 .10^{14}$ & 1357.86 & 36.34 & 10.48 \\
$\mathbf{5 0 0 0}$ & $1.84 .10^{13}$ & 1359.60 & 81.59 & 659.88 \\
\hline
\end{tabular}

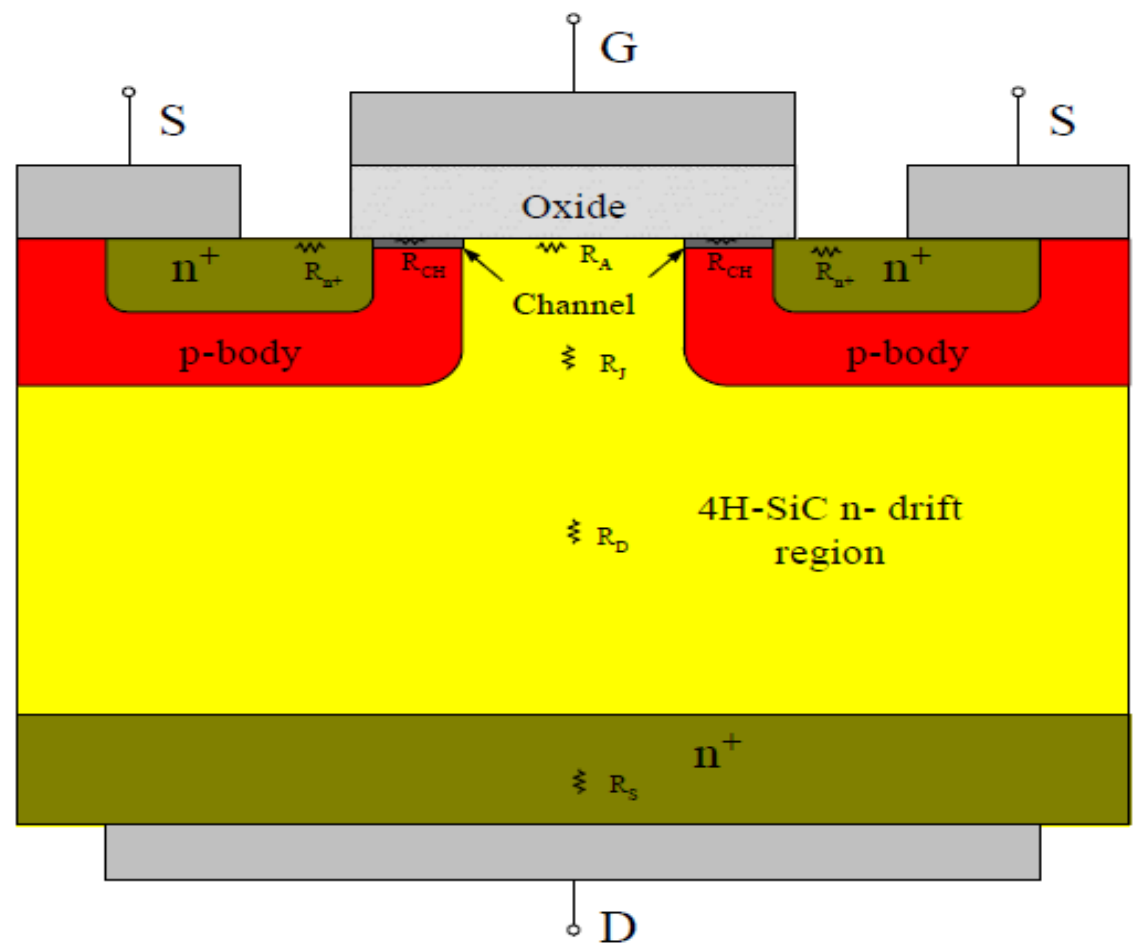

Figure 2. Schematic cross section of vertical DIMOS structure 


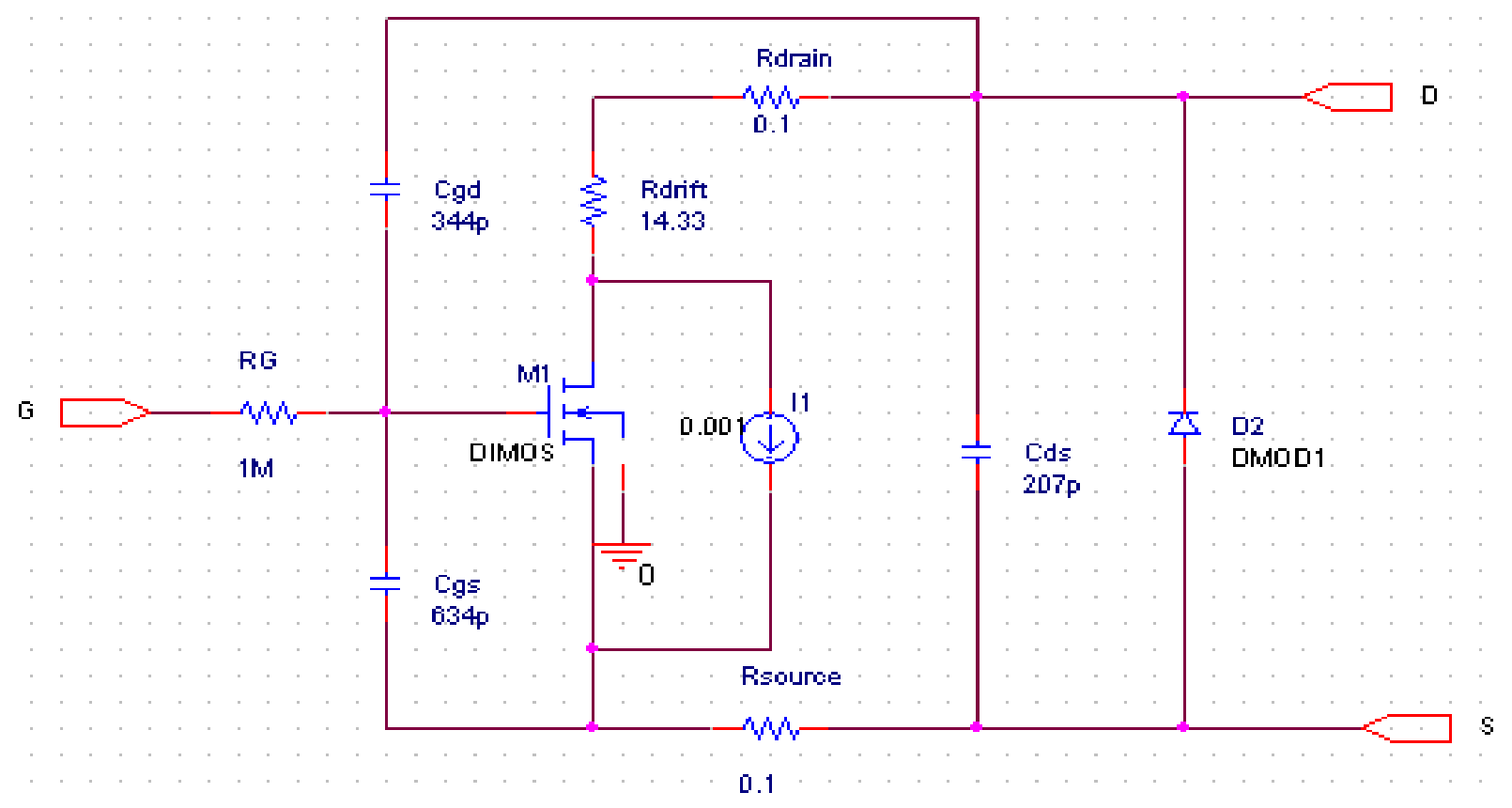

Figure 3. Equivalent SPICE model of $4 \mathrm{H}-\mathrm{SiC}$ MOSFET transistor

\section{Macromodel Structure}

A simple behavioural SPICE model for the SiC DIMOSFET is proposed based on the understanding of the power MOSFET device terminal behaviour (Figure 3). The aim of the model development is to reuse the available built-in FET models of the regular lateral MOS devices of the commercial SPICE simulator[11]. The advantage of the model is the limited number of required parameters, which can readily be extracted from simple terminal measurements or from standard datasheets, using the algorithmic and empirical approach as described below. Once the parameters are placed, the model can be used to simulate either p-channel or $\mathrm{n}$-channel $\mathrm{SiC}$ power MOSFET devices over a wide range of currents and voltages.

The model especially considers silicon carbide material and process related parameters that affect the device performance. The model can be described as a sub-circuit within the same SPICE code and can be run in any commercial SPICE simulator. Since DIMOS is a power device, its channel length, width, and other device dimensions are big enough to neglect the second order effects in the model equations, and the simulation can be carried out as SPICE level 1 or level 2[12-13].

Due to larger gate area, power MOSFETs show large gate capacitance. The major three capacitances considered in the model are: gate-source capacitance $\left(\mathrm{C}_{\mathrm{GS}}\right)$, gate-drain capacitance $\left(\mathrm{C}_{\mathrm{GD}}\right)$, and drain-source capacitance $\left(\mathrm{C}_{\mathrm{DS}}\right)$. These capacitances show considerable effects on switching characteristics or dynamic behavior of the device.
Power 4H- SiC MOSFETs model represented in Figure 4 can block the voltage in reverse bias condition. This blocking capability is usually represented by the reverse bias body diode, which is formed between the p-bodies and n-drift region of the vertical structure. The effect of channel resistance variation with gate bias is represented by the dependent current source $I_{R C H}$. The current from the dependent current source increases with an increase in the gate voltage. The proportionality constant of the dependent current is determined from the empirical fit of the measured data[14-16].

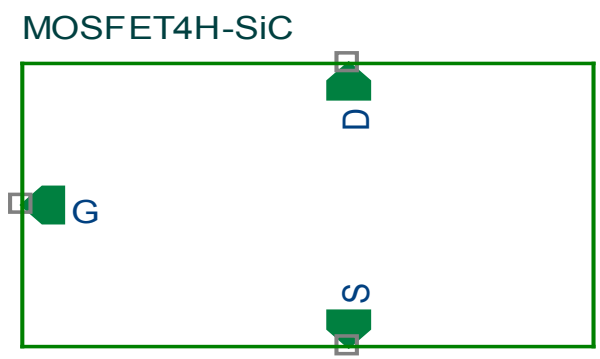

Figure 4. The model of $4 \mathrm{H}-\mathrm{SiC}$ MOSFET inserted in Spice library

\section{Simulation Results}

The figures below show typical DC simulation results. The model is able to reproduce thestrong quasisaturation effect in the devices and still retain a good fit for the currents nearthreshold. 


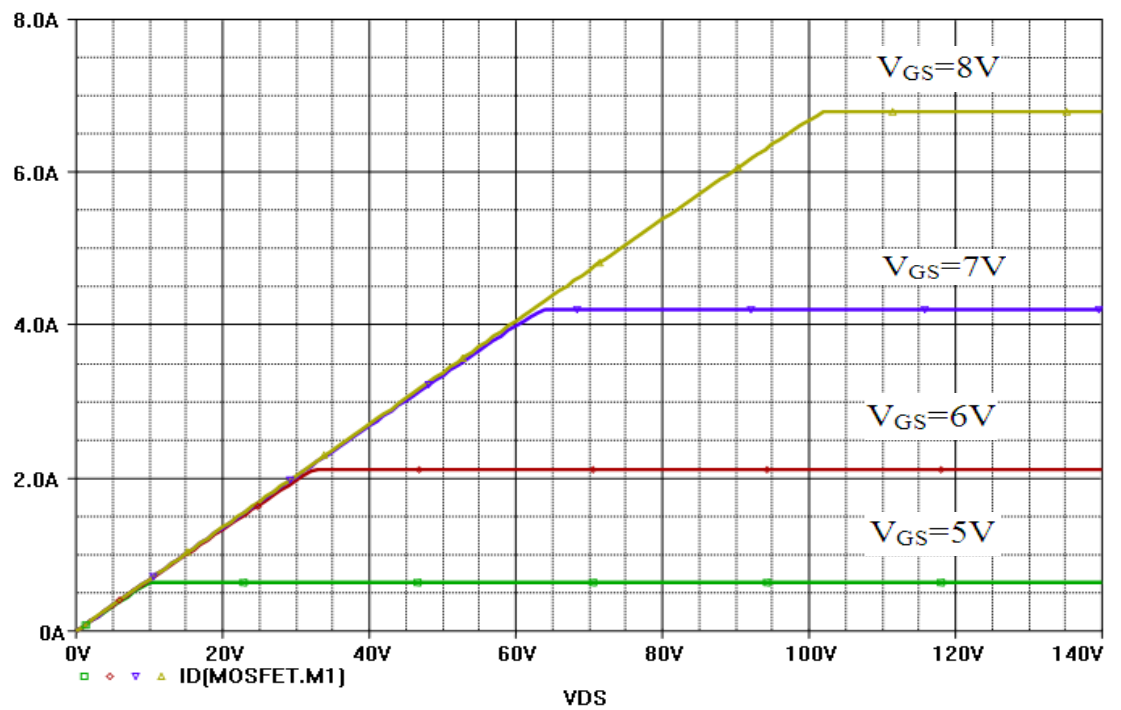

Figure 5. Forward charact erist ic simulation of $4 \mathrm{H}-\mathrm{SiC}$ MOSFET

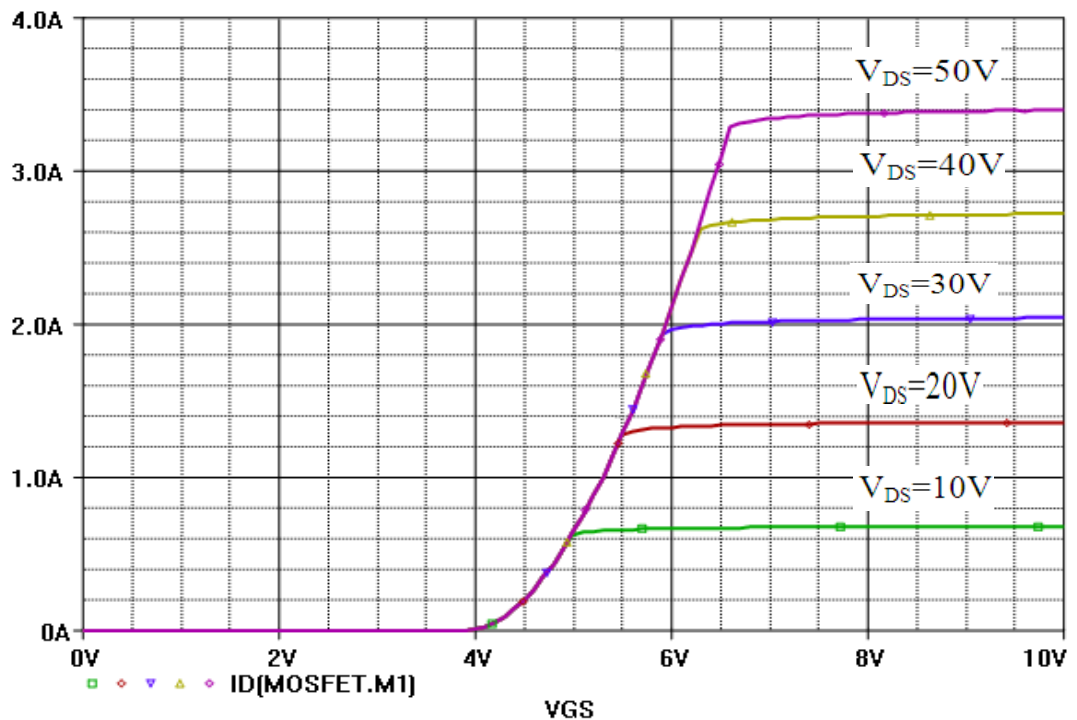

Figure 6. Characterization of $I_{D}$ versus $V_{G S}$ by stepping $V_{D S}$

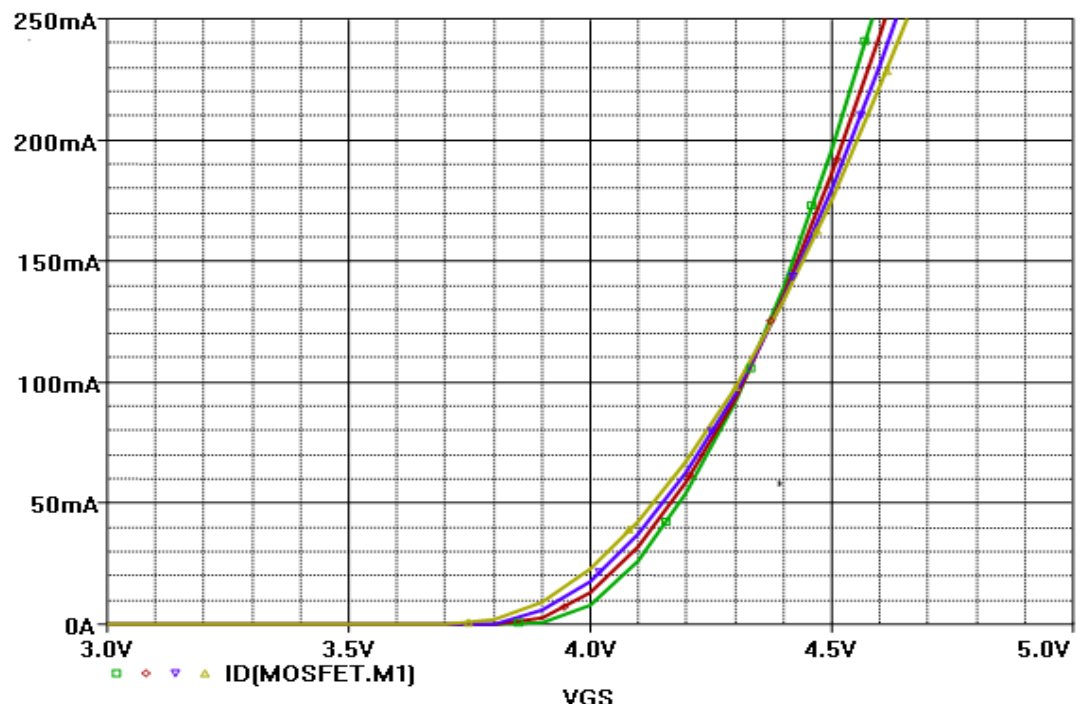

Figure 7. Transfer characteristics of $4 \mathrm{H}-\mathrm{SiC}$ MOSFET at different temperat ure: $\mathrm{T}=50^{\circ} \mathrm{C}, 100^{\circ} \mathrm{C}, 150^{\circ} \mathrm{C}$ and $200^{\circ} \mathrm{C}$ (Green to Yellow) 


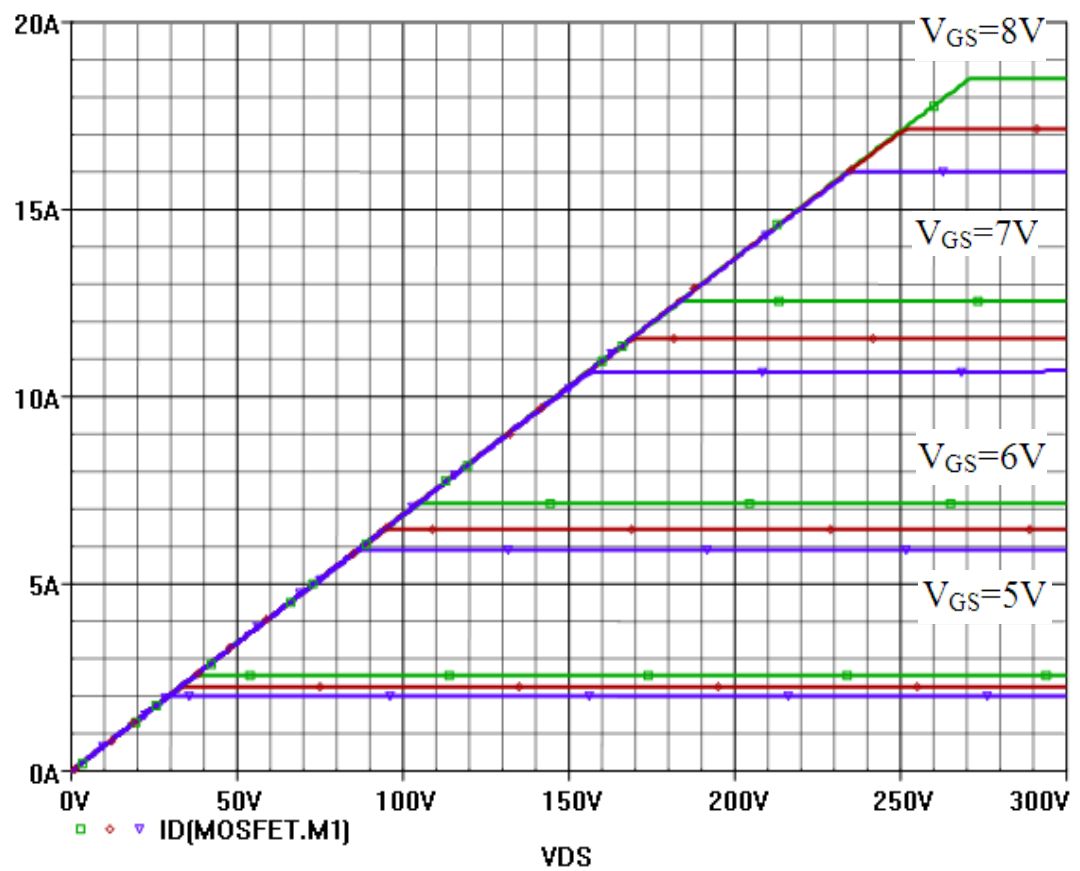

Figure 8. Forward characteristic simulation of $4 \mathrm{H}-\mathrm{SiC}$ MOSFET at $\mathrm{T}=50^{\circ} \mathrm{C}, 100^{\circ} \mathrm{C}$ and $150^{\circ} \mathrm{C}$ (Green to Blue)

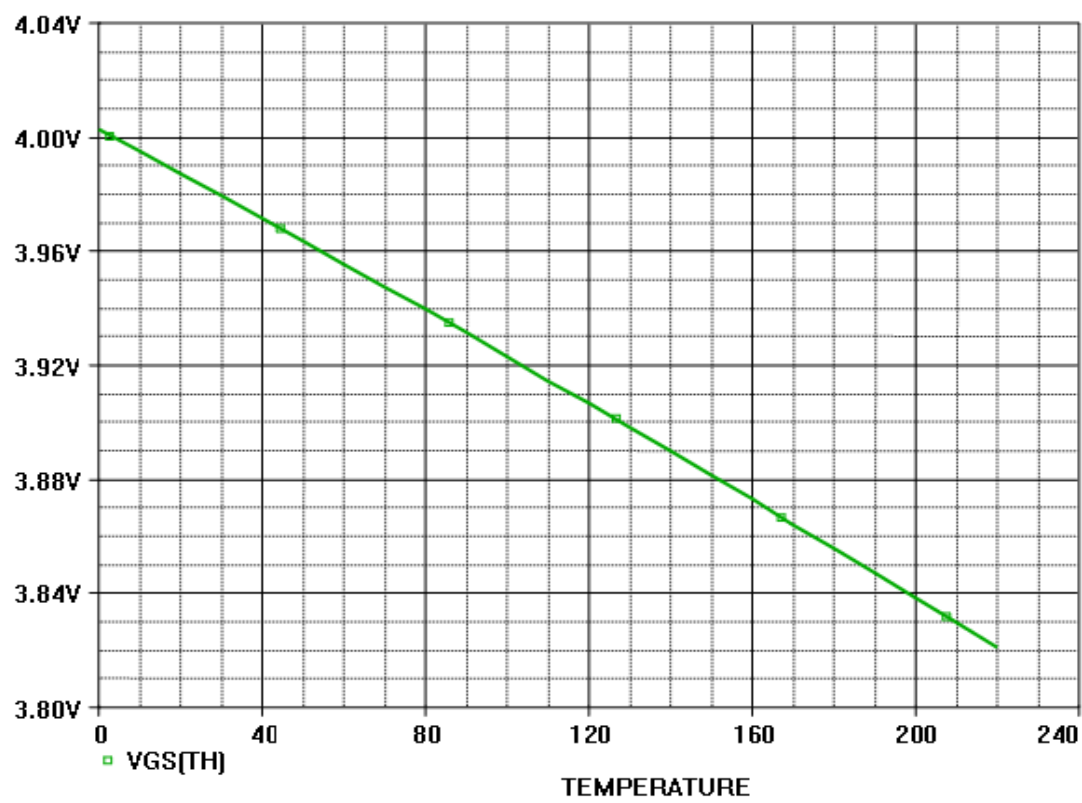

Figure 9. Threshold voltage simulation of $4 \mathrm{H}-\mathrm{SiC}$ MOSFET $\left(\mathrm{I}_{\mathrm{D}}=50 \mathrm{~mA}\right.$ and $\left.\mathrm{V}_{\mathrm{DS}}=\mathrm{V}_{\mathrm{GS}}\right)$

\section{Conclusions}

In this paper, a vertical double implantedMOSFET in $4 \mathrm{H}-\mathrm{SiC}$ material system for power electronic applications has been tested and modelled. The static characteristics, such as the forward and trans fer curves and threshold voltage have been extracted and simulated under different temperatures, the macro model of $4 \mathrm{H}-\mathrm{SiC}$ DIMOSFET has been developed and inserted in the SPICE library. A device structure is also proposed to verify the model in $4 \mathrm{H}-\mathrm{SiC}$ material. Temperature effect in DIMOS is observed. The temperature effects imposed on the drift region doping help to achieve a device structure for the desired current level and breakdown voltage. All SPICE parameters are extracted from the measured data. The simulation results matched very well with the measurements. The advantages of $\mathrm{SiC}$ power devices can be further demonstrated by somecircuit simulation, for example, an unclamped inductance circuit.

\section{ACKNOWLEDGMENTS}

The author would like to thank Mr. Lotfi khadraoui for his great help.

\section{REFERENCES}


[1] B. Hull, M. Das, F. Husna, R. Callanan, A. Agarwal, and J.Palmour, "20A, $1200 \mathrm{~V}$ 4H-SiC DMOSFETs for Energy ConversionSystems," presented at the 2009 IEEE Energy Conversion Congressand Exposition, San Jose, California.

[2] S. Ryu et al. "High Speed Switching Devices in 4H-SiC Performance and Reliability", presented at ISDRS 2005, December 7-9, 2005, Baltimore, MD.

[3] M. Chinthavali, B. Ozpineci, L. M. Tolbert, "Hightemperature andhigh-frequency performance evaluation of 4H-SiC unipolar powerdevices," Applied Power Electronics Conference and Exposition, 6-10M arch 2005, pp. 322-328.

[4] Y. Tang and T. P. Chow, "Monolithic 4H-SiC Darlington transistorswith peak current gain of 2000," in Proc. 61 $1^{\text {th }}$ IEEE Device ResearchConf., Salt Lake City, UT, 2003, pp. 183-184.

[5] Z. Chen, D. Boroyevich, R. Burgos, F. Wang, "Characterization and modeling of $1.2 \mathrm{kV}, 20 \mathrm{~A}$ SiCMOSFETs," IEEE Energy ConversionCongress and Exposition (ECCE), 20-24 Sept. 2009, pp. 1480-1487.

[6] A. Perez-Tomas et al, "Field-effect electron mobility model for SiC MOSFETs including high density of traps at the interface", Microelectronics Engineering, No. 83, pp. 440-445, 2006.

[7] S.-H. Ryu, S. Krishnaswami, B. Hull, B. Heath, M. Das, J. Richmond,A. A garwal, and J. Palmour, "Development of 8 $\mathrm{m} \Omega-\mathrm{cm} 2,1.8 \mathrm{kV}$ 4H-SiCDMOSFETs," Mater. Sci. Forum, 527-529, 1261-1264 (2006).

[8] M. Hasanuzzaman, Islam SK, Tolbert LM. Effect oftemperature variation (300-600K) in Mosfet modelingin $6 \mathrm{H}$ silicon carbide. Solid State Electron 2004;48(1):125-32.

[9] M. Hasanuzzaman, S. K. Islam, and L. M. Tolbert, "Model simulation and verification of vertical double implanted
(DIMOSFET) transistor in 6H-SiC", Int. J. Modelling andSimulation, 2003, 4, 1-4.

[10] VickramR. Vathulya, Marvin H. White"Characterization and performance comparison of the power DIMOS structure fabricated with a reduced thermal budget in $4 \mathrm{H}$ and 6H-SiCSolid-State Electronics 44 (2000) 309-315

[11] J. Wang, T. Zhao, J. Li, A. Q. Huang, R. Callanan, F. Husna, A. Agarwal, "Characterization, modeling, and application of 10-kV SiC MOSFET," IEEE Transactions on Electron Devices, vol. 55, no. 8, pp. 1798 1806, Aug. 2008.

[12] a. Ohtani N., Katsuno M., Nakabayachi M., Fujimoto T., Tsuge H., Yaschiro H., Aigo T.,Hirano H., Hoshino T., Tatsumi K., Investigation of heavily nitrogen-dopedn+ $4 \mathrm{H}-\mathrm{SiC}$ crystals grown by physical vapor transport, Journal of Crystal Growth,2009, 311,6, pp: 1475-1481.

[13] J. N. Shenoy, J. A. Cooper, and M. R. Melloch, "High-voltage double-implanted power MOSFET's in 4H-SiC", IEEE Trans. Electron Device Lett., 1997, 18, 93-95.

[14] J. A. Cooper, M. R. Melloch, R. Singh, A.Aggarwal, and J. W. Palmour, "Status and prospectfor SiC MOSFET", IEEE Trans. Electron Devices, 2002, 49, 658-664

[15] N. Phankong, T. Funaki, T. Hikihara, "A static and dynamic model fora silicon carbide power MOSFET," 13th European Conference on Power Electronics and Application , 8-10 Sept. 2009, pp. 1-10.

[16] S. Kagamihara, H. Matsuura, "Parameters required to simulate electriccharacteristics of $\mathrm{SiC}$ devices for n-type 4H-SiC," Journal of AppliedPhy sics, vol. 96, no.10, 15 Nov. 2004, pp. 5601-5606. 